\title{
One-step Oxidation of Total Organic Carbon, Total Nitrogen, and Total Phosphorous using Wet Chemical Oxidation
}

\author{
Jeong-Hwan Choi $^{\oplus} \cdot$ Dong-Hun Shin ${ }^{\oplus} \cdot$ Hye-Bin Kim $^{\oplus} \cdot$ Jong-Gook Kim ${ }^{\oplus} \cdot$ Kitae Baek $^{\dagger}$ \\ Department of Environment \& Energy and Soil Environment Research Center, Jeonbuk National University
}

(Received September 16, 2020; Revised November 2, 2020; Accepted November 18, 2020)

Objective : This study proposed the simultaneous multi-oxidation of total organic carbon, total nitrogen, and total phosphorous using modified wet chemical oxidation method.

Methods: The multi oxidation process was based on the dual radical system with sulfate and hydroxyl radicals. The sodium persulfate $\left(\mathrm{Na}_{2} \mathrm{~S}_{2} \mathrm{O}_{8}\right)$ and sodium hydroxide $(\mathrm{NaOH})$ were activated at $40^{\circ} \mathrm{C}$ and UV irradiation with $254 \mathrm{~nm}$ to generate the sulfate radical and hydroxyl radical. The organic matters were oxidized by the dual radicals, and TOC, TN, and TP values were compared with the control group.

Results and Discussion: The dual radical system oxidized organic carbon to carbon dioxide effectively, and the TOC values were similar to the value obtained from the high-temperature combustion technique. However, the residual persulfate after oxidation process interfered the absorbance for TN and inhibit the complexation in TP measurement. The residual persulfate was effectively converted to sulfate by longer heating and UV irradiation, and the interferences were more sensitive to reaction temperature than UV irradiation time. As a result, a higher temperature condition was more effective and enhanced the applicability of multi-oxidation.

Conclusions: The multi oxidation of TOC, TN, and TP was demonstrated by wet chemical oxidation, and the proposed method is expected to secure the sample and reduce the analytic time. However, the more suitable condition to enhance the accuracy of TOC, TN, and TP in the multi-oxidation system should be studied further.

Keywords: Wet Chemical Oxidation (WCO), Radical Oxidation, Total Organic Carbon (TOC), Total Nitrogen (T-N), Total Phosphorous (T-P)

The Korean text of this paper can be translated into multiple languages on the website of http://jksee.or.kr through Google Translator. 


\title{
연구논문
}

\section{습식산화를 이용한 TOC, T-N, T-P 동시산화 연구}

\author{
최정환 ${ }^{\odot} \cdot$ 신동훈 $^{\oplus} \cdot$ 김혜빈 $^{\circledR} \cdot$ 김종국 $^{\circledR} \cdot$ 백기태 $^{\dagger}$ \\ 전북대학교 환경에너지융합학과 및 토양환경연구센터
}

목적: 본 연구는 습식산화 방법을 활용하여 총 유기탄소(TOC), 총 질소(T-N), 총 인(T-P)의 동시산화 및 측정 가능 성을 확인하였다.

방법 : 유기질소 및 유기인을 포함하는 시료에 과황산나트륨 $\left(\mathrm{Na}_{2} \mathrm{~S}_{2} \mathrm{O}_{8}\right)$ 과 수산화나트륨 $(\mathrm{NaOH})$ 을 공급하고 UV 254 $\mathrm{nm}$ 및 $40^{\circ} \mathrm{C}$ 조건에서 황산라디칼 $\left(\mathrm{SO}_{4}{ }^{-} \cdot\right)$ 과 수산화라디칼 $(\mathrm{OH} \cdot)$ 의 활성화를 유도했다. 생성된 2종류의 라디칼을 통 해 시료를 산화하고 TOC, T-N, T-P값을 공정시험법으로 분석한 대조군과 비교하여 동시산화 가능성을 평가하였다.

결과 및 토의: 본 연구에서 제안한 습식산화방법은 $0.3 \mathrm{M}$ 의 낮은 과황산염 농도를 사용하였으나 모든 시료에서 고온 연소산화기기에 대응하는 TOC 측정 결과 값을 나타내어 우수한 산화력을 증명했다. 또한 실험과정에서 발생한 T-N, T-P 측정오차를 개선하기 위해 제안된 추가공정은 UV-VIS 측정 간섭을 감소시켰다. 두 지표에서 모두 UV 처리보다 열처리가 간섭 제거에 더 효과적이었으며 온도와 시간이 증가할수록 그 효과가 극대화되는 것으로 나타났다.

결론 : 습식산화를 활용하여 세 지표를 동시에 측정할 수 있음을 확인하였다. 제안된 방법은 적은 시료로 단시간에 세 지표를 분석할 수 있을 것으로 기대된다. 그러나 정확도를 향상시키기 위해 방해요인을 보다 효과적으로 제거 할 수 있는 방법에 대한 추가적인 연구가 필요하다.

주제어 : 습식산화, 라디칼산화, 총 유기탄소(TOC), 총 질소(T-N), 총 인(T-P)

\section{1. 서론}

지속적인 산업고도화에 따라 많은 양의 유기화학물질이 생산되고 수계로 유입되고 있으며, 이는 수질을 악화시키는 원인물질로 지목되고 있다. ${ }^{1,2)}$ 이에 따라, 수중 유기물은 생 물학적산소요구량(BOD)과 화학적산소요구량 $(\mathrm{COD})$ 과 같 은 전통적인 지표를 사용하여 평가되었다. 하지만 $\mathrm{BOD}$ 와 $\mathrm{COD}$ 는 실제 유기물의 정확한 양을 보여주지 못하고, 분석 에 긴 시간이 소요되며, 최근 증가하고 있는 난분해성 유기 물질은 포함되지 않는 등의 단점이 있다. ${ }^{3-5)}$ 이러한 BOD 및 $\mathrm{COD}$ 의 단점으로 인해 용존 유기물량을 정확히 측정할 수 있는 지표로 총 유기탄소(TOC)에 대한 관심이 지속적으로 증가하고 있다. ${ }^{4,6,7}$

유기물뿐만 아니라 화학비료와 합성세제의 사용으로 인 해 수계로의 영양염류의 유출이 지속적으로 증가하고 있으 며), 과도한 영양염류 유입은 수계에서 조류의 과잉 성장으 로 이어져 부영양화를 유발한다. ${ }^{9,10)}$ 빠른 속도로 증가하는 식물성플랑크톤은 용존산소를 소모하고 수계의 유기물 부 하를 증가시켜 수질을 악화시킨다. 또한 다량의 식물성플랑
크톤은 수표면을 덮어 빛의 투과를 감소시키고, 수중 생물 의 광합성을 방해하여 수생태계를 지속적으로 파괴한다. ${ }^{11)}$ 따라서, 영양염류 중 식물성플랑크톤 성장에 핵심 성분인 질소와 인을 총 질소(T-N)와 총 인(T-P)으로 측정하여 수질 지표로 활용하고 있으며 이들은 TOC와 더불어 수질을 파 악하는 주요 인자이다. ${ }^{12-14)}$

이처럼 수질 지표에 대한 분석방법과 분석기기에 대한 연 구가 지속적으로 진행되고 있다. 본 연구에서는 3 가지 지표 가 모두 산화제를 사용하여 대상 물질을 각각 이산화탄소 $\left(\mathrm{CO}_{2}\right)$, 질산염 $\left(\mathrm{NO}_{3}{ }^{-}\right)$, 인산염 $\left(\mathrm{PO}_{4}{ }^{3-}\right)$ 의 산화형태로 전환시킨 후 이를 측정하는 공통점을 활용하여 ${ }^{15,16)}$ 한 반응기 내에서 동시산화의 가능성을 확인하고자 했다. TOC, T-N, T-P 동시 산화는 주입되는 시료와 시약의 양을 약 $1 / 3$ 가량 줄일 뿐만 아니라 폐액의 양도 현저히 감소시킬 수 있다. 또한, 산화효 율을 향상시키기 위해 황산염 라디칼 $\left(\mathrm{SO}_{4}^{-} \cdot\right)$ 을 사용하는 기 존의 습식산화 방식에 추가적으로 수산화 라디칼 $(\mathrm{OH} \cdot)$ 을 생성하는 복합 라디칼방식(DRS, Dual-Radical System)을 구 현하고 이를 통해 TOC, T-N, T-P를 동시에 산화하여 측정 할 수 있는지를 평가하고자 했다. 이를 반영하여 본 연구는 
Table 1. Organic nitrogen and phosphorus chemicals for identification of multi oxidation.

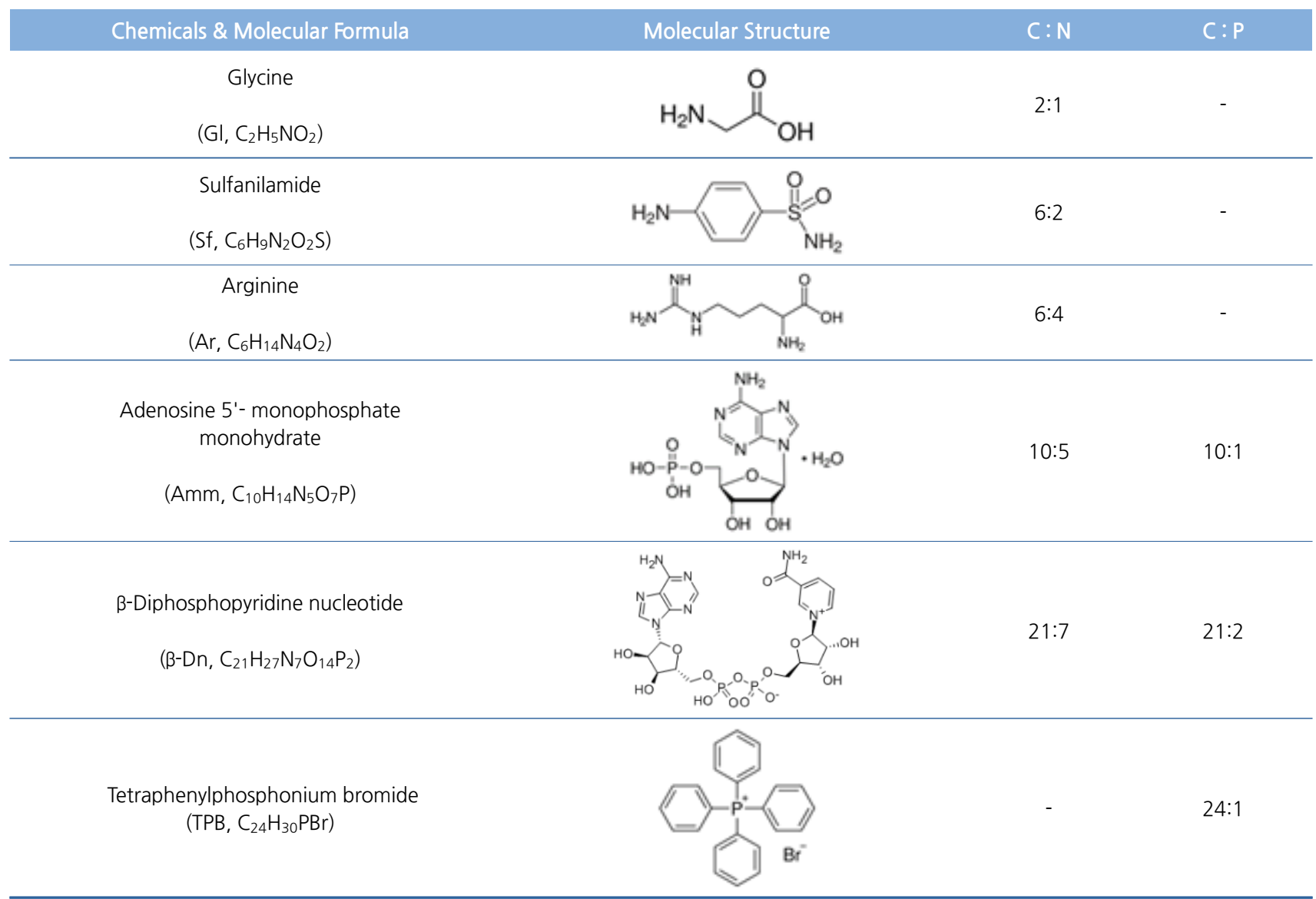

유기 질소와 인을 함유한 다양한 화학 물질을 대상으로 $\mathrm{DRS}$ 를 이용한 TOC, T-N, T-P의 산화 효율을 기존의 습식 산화 방법 및 공정시험기준과 비교하였다.

\section{2. 실험방법}

\section{1. 실험재료}

본 연구는 과황산나트륨 $\left(\mathrm{Na}_{2} \mathrm{~S}_{2} \mathrm{O}_{8}, 98.0 \%\right.$, Junsei), 황산 $\left(\mathrm{H}_{2} \mathrm{SO}_{4}, 85.0 \%\right.$, Samchun), 수산화나트륨용액 $(\mathrm{NaOH}$, Solution $50 \%$ in $\mathrm{H}_{2} \mathrm{O}$, Sigma-Aldrich)을 사용하여 산화환경을 구현하 였으며, 이들은 다음의 반응식을 통해 두 가지 라디칼 $\left(\mathrm{SO}_{4}{ }^{-}\right.$, $\mathrm{OH} \cdot)$ 을 형성한다. ${ }^{17-20)}$

Reaction 1: $\mathrm{S}_{2} \mathrm{O}_{8}{ }^{2-} \rightarrow 2 \mathrm{SO}_{4}{ }^{-}$

Reaction 2: $\mathrm{SO}_{4}{ }^{-} \cdot+\mathrm{OH}^{-} \rightarrow \mathrm{SO}_{4}{ }^{2-}+\mathrm{OH}$.

유기질소의 산화능을 평가하기 위해 Glycine (Gl, $\geq 99.0 \%$, Samchun), Sulfanilamide (Sf, $\geq 99.0 \%$, Sigma-Aldrich), Arginine (Ar, $\geq 98.0 \%$, Samchun)을 예상 유기질소 농도 $30 \mathrm{mg} \mathrm{N} / \mathrm{L}$ 액상시료를 제조한 후 $\mathrm{DRS}$ 를 사용하여 산화한 후 T-N 값 을 측정하였다. 또한, 유기인의 산화능을 평가하기 위해서
Adenosine 5'- monophosphate monohydrate (Amm, $\geq 97.0 \%$, Sigma-Aldrich), $\beta$-Diphosphopyridine nucleotide ( $\beta$-Dn, $\geq$ 99.0\%, Sigma-Aldrich), Tetraphenylphosphonium bromide (TPB, $\geq 98.0 \%$, Sigma-Aldrich)을 유기인 농도 $10 \mathrm{mg}$ P/L 액상시료 로 제조한 후 이를 산화하여 T-P 값을 측정하였다. 위의 6가 지 대상물질은 황산라디칼의 산화력을 억제하는 할로겐이온 을 함유하거나, 벤젠고리와 같은 안정적인 구조를 가지고 있 어 산화하기 어려운 물질을 포함하고 있고, 그 구조 및 특성

은 Table 1에 요약하였다.

또한, TOC, T-N, T-P 측정에 필요한 검량선을 작성하기 위 해 Potassium hydrogen phthalate (KHP, $\mathrm{C}_{8} \mathrm{H}_{5} \mathrm{KO}_{4}, 99.5 \%$, EP, Daejung), Potassium nitrate $\left(\mathrm{KNO}_{3}, \geq 99 \%\right.$, Sigma-Aldrich), mono-Potassium phosphate $\left(\mathrm{KH}_{2} \mathrm{PO}_{4}, \geq 98 \%\right.$, EP, Junsei)과 같은 표준물질을 사용하였다.

\section{2. 실험방법}

$\mathrm{DRS}$ 의 산화효율을 평가하기 위해 기존의 습식산화방법 (WCO, wet chemical oxidation)으로 산화한 시료를 대조군으 로 활용하였다. 고온연소산화기기(HTC, Shimadzu, TOC-L, Japan)를 사용하여 각 시료의 TOC 및 T-N농도를 측정했으멸, 아스코르빈산법을 사용하여 과황산칼륨 $\left(\mathrm{K}_{2} \mathrm{~S}_{2} \mathrm{O}_{8}\right)$ 과 혼합한 


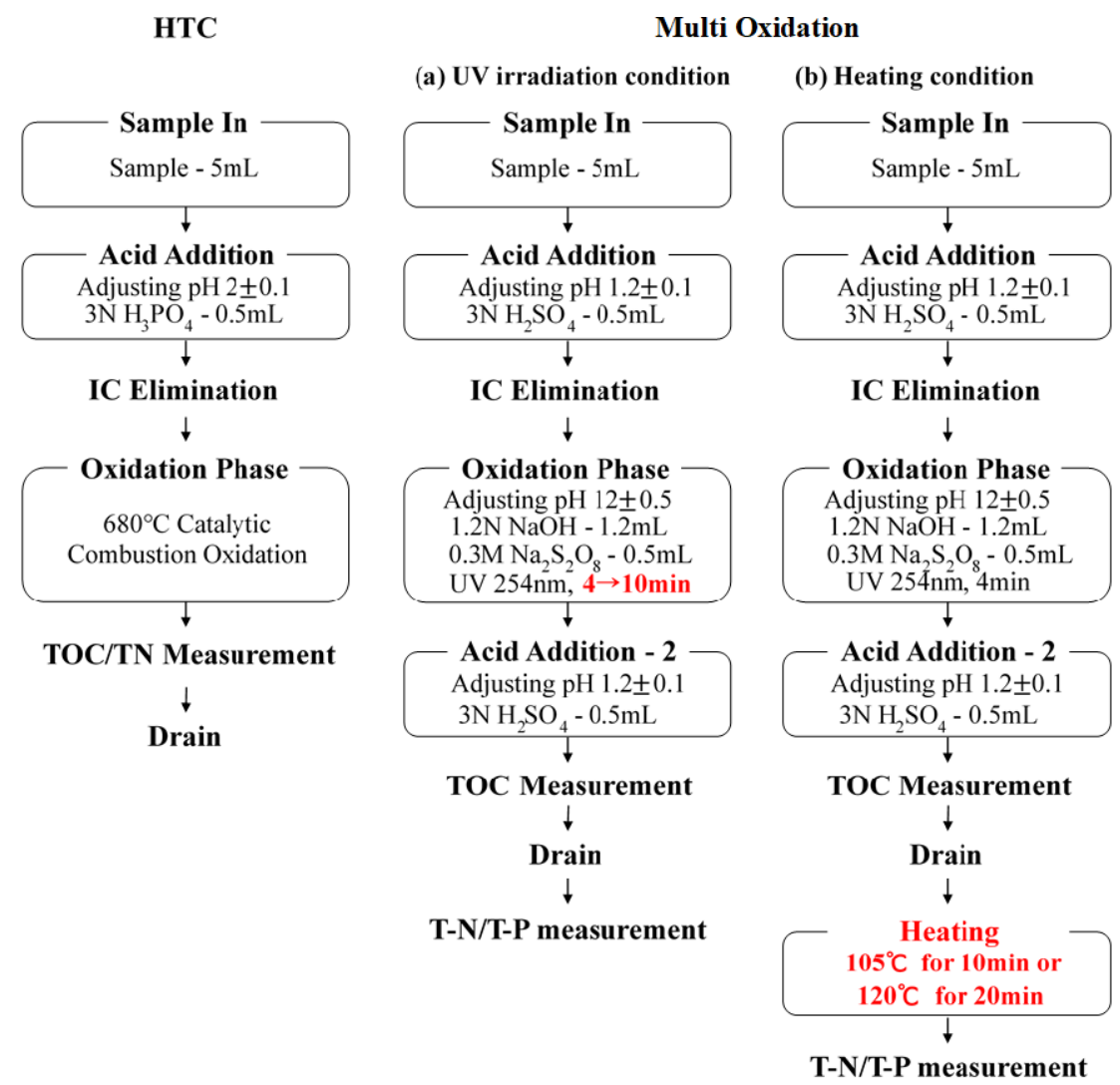

Fig. 1. Sequence of oxidation method used in this study.

시료를 $120^{\circ} \mathrm{C}$ 에서 30 분 동안 가열한 후 식혀 발색한 시료를 $880 \mathrm{~nm}$ 에서 UV-VIS (HS-3700, Humas)로 측정하여 T-P농도 를 측정하였다.

동시산화는 Fig. 1 의 순서도를 따라 진행되었다. 우선 반 응기 내 $\mathrm{pH}$ 를 산성조건으로 조절하여 무기탄소를 제거하였 다. 산화단계에서는 기존 습식산화 방식에 수산화나트륨을 추가적으로 공급하고 $\mathrm{pH}$ 조절에 사용되는 인산 $\left(\mathrm{H}_{3} \mathrm{PO}_{4}\right)$ 대신 황산 $\left(\mathrm{H}_{2} \mathrm{SO}_{4}\right)$ 을 사용하여 인산염에 의한 $\mathrm{T}-\mathrm{P}$ 분석의 간섭효 과를 차단하였다. 특히, 산화제인 과황산나트륨 $\left(\mathrm{Na}_{2} \mathrm{~S}_{2} \mathrm{O}_{8}\right)$ 이 빛을 흡수하는 특징을 가지고 있어 분석 후 잔류하는 과황 산이 분석에 오차를 발생할 수 있다. 따라서 잔류하는 과황 산의 양을 줄이기 위해 기존 습식산화공정에서 사용하던 과 황산나트륨의 농도인 $1 \mathrm{M}$ 대신 $0.3 \mathrm{M}$ 로 적용하였다. 유입 된 시료는 $40^{\circ} \mathrm{C}$ 에서 $254 \mathrm{~nm}$ 의 $\mathrm{UV}$ 조사하여 $\mathrm{TOC}$ 값을 측정 한 후 배출된다. 배출시료는 공정시험기준에 따라 UV-VIS 를 사용하여 T-N값은 $220 \mathrm{~nm}$ 에서, T-P값은 발색 후 $880 \mathrm{~nm}$ 에서 분석하고 대조군과 비교하여 동시산화 기기의 효율을 평가하였다.

그러나, 제안된 동시산화 공정은 여전히 UV-VIS 측정에 간섭문제를 보여 배출된 시료를 후처리하는 공정을 추가했 다. 추가 공정은 잔류하는 과황산을 제거하기 위해 UV조사 시간을 증가하거나(Fig.1(a)) 반응온도를 변화시켰으며(Fig. 1(b)), 세부 조건을 산정하기 위해 공정을 거친 증류수를 대
상으로 실험을 진행했다. 추가 실험을 통해 UV시간 10 분, $105^{\circ} \mathrm{C} 10$ 분 열처리, $120^{\circ} \mathrm{C} 20$ 분 열처리로 후처리 공정을 선 정하여 실험을 진행하였다.

\section{3. 결과 및 고찰}

\section{1. 총 유기탄소(TOC) 산화 확인}

TOC, T-N, T-P를 동시에 산화하고 각 값을 분석한 결과를 각각 Table 2, 3, 4에 정리하였다. 산화제 농도를 $0.3 \mathrm{M}$ 로 낮추었기 때문에 유기물의 산화효율이 감소할 가능성이 있 으므로 $\mathrm{TOC}$ 를 측정하여 유기물의 완전산화가 먼저 입증되 어야 한다. Table2에서 효율 값은 기존 고온연소(HTC)기기 와 비교하여 본 연구에서 제안한 동시산화기기(Multi)의 $\mathrm{TOC}$ 값의 비율로 표현하였으며, 두 값의 오차가 $\pm 20 \%$ 의 이 내의 범위이기 때문에 유기물의 이산화탄소로의 산화가 적 절하게 이루어진 것으로 판단하였다. 결과적으로 세 가지 산화조건에서 동시산화공정의 유기물 산화는 $\mathrm{HTC}$ 와 대등 한 값을 보여주었으며 낮은 산화제 농도에서도 충분한 유기 물 산화능력을 갖추었다고 판단하였다.

\section{2. 총 질소(T-N) 동시산화 검증}

Table 3에서 동시산화기기(Multi)의 세 가지 후처리 공정 중 UV 10 분 추가 조사 및 $105^{\circ} \mathrm{C}$ 에서 10 분의 추가 열처리 
Table 2. TOC concentration of organic nitrogen and phosphorus by HTC and multi equipment.

\begin{tabular}{|c|c|c|c|c|}
\hline \multirow{2}{*}{ Method } & \multirow{2}{*}{ Chemicals } & \multicolumn{2}{|c|}{$\mathrm{TOC}(\mathrm{mg} / \mathrm{L})$} & \multirow{2}{*}{$\frac{\text { Efficiency (\%) }}{\text { Multi/HTC }}$} \\
\hline & & HTC & Multi & \\
\hline \multirow{6}{*}{$\begin{array}{l}\text { UV irradiation } \\
\text { for } \\
10 \mathrm{~min}\end{array}$} & $\mathrm{Gl}$ & $47.53 \pm 0.45$ & $55.04 \pm 0.16$ & 115.80 \\
\hline & Sf & $72.05 \pm 0.54$ & $73.22 \pm 0.25$ & 101.62 \\
\hline & $\mathrm{Ar}$ & $30.94 \pm 0.04$ & $31.43 \pm 0.14$ & 101.60 \\
\hline & Amm & $31.36 \pm 0.72$ & $33.10 \pm 0.02$ & 105.53 \\
\hline & $\beta-D n$ & $27.95 \pm 0.42$ & $29.84 \pm 0.21$ & 106.76 \\
\hline & TPB & $83.81 \pm 0.70$ & $89.18 \pm 1.29$ & 106.41 \\
\hline \multirow{6}{*}{$\begin{array}{l}105^{\circ} \mathrm{C} \\
\text { for } \\
10 \mathrm{~min}\end{array}$} & $\mathrm{Gl}$ & $47.53 \pm 0.45$ & $54.76 \pm 0.27$ & 115.21 \\
\hline & Sf & $72.05 \pm 0.54$ & $67.91 \pm 1.14$ & 94.25 \\
\hline & $\mathrm{Ar}$ & $30.94 \pm 0.04$ & $29.93 \pm 0.16$ & 96.75 \\
\hline & Amm & $31.36 \pm 0.72$ & $33.62 \pm 0.02$ & 107.19 \\
\hline & $\beta-D n$ & $27.95 \pm 0.42$ & $30.33 \pm 0.05$ & 108.53 \\
\hline & TPB & $83.81 \pm 0.70$ & $85.76 \pm 3.40$ & 102.34 \\
\hline \multirow{6}{*}{$\begin{array}{l}120^{\circ} \mathrm{C} \\
\text { for } \\
20 \mathrm{~min}\end{array}$} & $\mathrm{Gl}$ & $47.53 \pm 0.45$ & $47.14 \pm 0.30$ & 99.18 \\
\hline & Sf & $72.05 \pm 0.54$ & $69.24 \pm 0.81$ & 96.10 \\
\hline & $\mathrm{Ar}$ & $30.94 \pm 0.04$ & $27.92 \pm 0.25$ & 90.24 \\
\hline & Amm & $31.36 \pm 0.72$ & $30.05 \pm 0.73$ & 95.83 \\
\hline & $\beta-D n$ & $27.95 \pm 0.42$ & $28.57 \pm 0.32$ & 102.22 \\
\hline & TPB & $83.81 \pm 0.70$ & $81.97 \pm 0.22$ & 97.80 \\
\hline
\end{tabular}

Table 3. T-N concentration of organic nitrogen by HTC and multi equipment.

\begin{tabular}{ccccc} 
Method & Chemicals & \multicolumn{2}{c}{ T-N (mg/L) } & Efficiency (\%) \\
\cline { 3 - 4 } UV irradiation & & HTC & Multi & 160.68 \\
for & $\mathrm{Gl}$ & $27.00 \pm 0.11$ & $43.38 \pm 1.62$ & 189.85 \\
$10 \mathrm{~min}$ & $\mathrm{Sf}$ & $22.17 \pm 0.11$ & $42.09 \pm 0.65$ & 111.58 \\
\hline $105^{\circ} \mathrm{C}$ & $\mathrm{Ar}$ & $23.25 \pm 0.01$ & $25.94 \pm 0.43$ & 153.91 \\
for & $\mathrm{Gl}$ & $27.00 \pm 0.11$ & $41.56 \pm 0.11$ & 141.41 \\
$10 \mathrm{~min}$ & $\mathrm{Sf}$ & $22.17 \pm 0.11$ & $31.35 \pm 0.54$ & 107.65 \\
\hline $120^{\circ} \mathrm{C}$ & $\mathrm{Ar}$ & $23.25 \pm 0.01$ & $25.03 \pm 0.22$ & 113.04 \\
$\mathrm{for}$ & $\mathrm{Gl}$ & $27.00 \pm 0.11$ & $30.52 \pm 0.36$ & 105.05 \\
$20 \mathrm{~min}$ & $\mathrm{Sf}$ & $22.17 \pm 0.11$ & $23.29 \pm 0.61$ & 102.49 \\
\hline
\end{tabular}

조건은 T-N값을 과대평가하였으며, 이는 위의 제시된 두 가 지 공정이 잔여 과황산염 $\left(\mathrm{S}_{2} \mathrm{O}_{8}{ }^{2-}\right)$ 을 완전히 활성화시키지 못 했음을 의미한다. 후처리 공정을 적용한 후 잔류하는 과황 산은 광범위한 파장의 UV를 흡수하는 특징이 있고, T-N 측 정에 사용되는 $220 \mathrm{~nm}$ 의 파장에서 광흡수를 통해 흡광도를 증가시켜 $\mathrm{T}-\mathrm{N}$ 의 과대 측정을 발생시켰다. 하지만, $120^{\circ} \mathrm{C} 20$ 분 추가 열처리조건에서 측정값은 $15 \%$ 의 오차범위 내에서 대조군에 유사한 값을 보여준다. 이 결과는 해당 후처리 조 건이 효과적으로 과황산을 활성화시켜 최종적으로 황산 형 태로 전환하였음을 의미한다. 결국 오차의 원인은 산화자체 의 문제라기보다는 잔류하는 과황산에 의한 간섭 효과이며 이에 대한 적절한 처리가 T-N의 안정적인 측정에 필수적이
라 판단된다.

\section{3. 총 인(T-P) 동시산화 검증}

T-P분석은 몰리브덴산 암모늄이 인산과 반응하여 생성되 는 인-몰리브덴산 암모늄을 환원시켜 생성되는 청색의 몰리 브덴 블루 착화물을 $880 \mathrm{~nm}$ 에서 흡광도를 측정하는 방식이 다. 본 실험에서 소모되지 못한 시료 내 잔여 과황산은 몰리 브덴 블루 착화물을 다시 산화시켜 발색을 방해하여 T-P에 대한 과소평가를 유발했다. Table 4에서 후처리 공정에 사 용된 열처리 온도 및 시간이 증가함에 따라 $\beta-\mathrm{Dn}$ 의 T-P값 이 개선되었다. 또한, $\mathrm{Amm}$ 및 $\mathrm{TPB}$ 는 두 조건에서 과대 평 가된 T-P값을 보여주었으나 실험 과정에서 주된 원인을 확 
Table 4. T-P concentration of organic phosphorus by ascorbic method and multi equipment.

\begin{tabular}{|c|c|c|c|c|}
\hline \multirow{2}{*}{ Method } & \multirow{2}{*}{ Chemicals } & \multicolumn{2}{|c|}{ T-P (mg/L) } & \multirow{2}{*}{$\begin{array}{c}\text { Efficiency (\%) } \\
\text { Multi / Ascorbic }\end{array}$} \\
\hline & & Ascorbic & Multi & \\
\hline \multirow{3}{*}{$\begin{array}{l}\text { UV irradiation } \\
\text { for } \\
10 \mathrm{~min}\end{array}$} & Amm & $9.43 \pm 0.01$ & $14.59 \pm 0.22$ & 154.71 \\
\hline & $\beta-D n$ & $8.02 \pm 0.02$ & $3.96 \pm 0.18$ & 49.41 \\
\hline & TPB & $9.16 \pm 0.08$ & $12.88 \pm 0.97$ & 140.67 \\
\hline \multirow{3}{*}{$\begin{array}{l}105^{\circ} \mathrm{C} \\
\text { for } \\
10 \mathrm{~min}\end{array}$} & Amm & $9.43 \pm 0.01$ & $15.79 \pm 0.26$ & 167.42 \\
\hline & $\beta-D n$ & $8.02 \pm 0.02$ & $4.75 \pm 0.09$ & 59.31 \\
\hline & TPB & $9.16 \pm 0.08$ & $12.77 \pm 0.04$ & 139.46 \\
\hline \multirow{3}{*}{$\begin{array}{c}120^{\circ} \mathrm{C} \\
\text { for } \\
20 \mathrm{~min}\end{array}$} & Amm & $9.43 \pm 0.01$ & $9.99 \pm 0.28$ & 105.94 \\
\hline & $\beta-D n$ & $8.02 \pm 0.02$ & $8.22 \pm 0.00$ & 102.49 \\
\hline & TPB & $9.16 \pm 0.08$ & $10.57 \pm 0.39$ & 115.39 \\
\hline
\end{tabular}

인하지 못했으며 이에 대한 추가연구가 요구된다. 결과적으 로, $120^{\circ} \mathrm{C} 20$ 분간 열처리하는 후처리 조건에서 세 실험군 모두 $20 \%$ 의 오차한계 내에서 대조군과 유사한 값을 나타냈 다. 따라서 실험을 통해 추가적인 UV 조사보다 열처리 조 건이 방해요인 제거에 효과적임을 증명하였으며, 이를 통해 동시산화공정에 대한 가능성을 확인하였다.

\section{4. 결론}

본 연구는 수질을 나타내는 대표인자인 총유기탄소(TOC), 총질소(T-N), 총인(T-P)을 동시에 측정하기 위해 습식산화를 활용하여 유기화학물질을 분석하였으며, 습식산화에 사용 되는 산화조건을 변경하거나 산화처리를 적용하고 후처리 공정을 통해 산화력을 향상시켜 TOC, T-N, T-P분석의 정확 성을 향상시키고자 하였다. 각 지표의 공정시험기준을 참고 하여 제조된 시료의 대조군을 형성하고 연구에서 제시한 동 시산화방법으로 측정된 결과값과 비교하여 산화 가능성을 판단하였다. 본 연구에서 얻은 결론은 다음과 같다.

1) 본 연구에서 제안한 습식산화방법은 $0.3 \mathrm{M}$ 의 낮은 산 화제 농도를 사용하였으므로 총 유기탄소(TOC) 값을 정상 적으로 산출하는지 검증했다. $\mathrm{TOC}$ 측정 결과, 모든 시료에 서 고온연소산화기기에 상응하는 값을 나타내어 TOC 산화 력을 입증하였다.

2) 실험과정에서 발생한 T-N, T-P 측정오차는 UV-VIS에 서 잔여 과황산염이 UV를 흡수하여 흡광도를 과측정하는 문제로 확인되었고, 이에 따라 본 연구는 산화공정 적용 후 잔류하는 과황산을 제거할 수 있는 후처리 공정으로 UV 조 사시간 증가 및 열처리를 선정하여 정확도를 향상시키고자 하였다. T-N측정에서는 후처리에 적용된 UV 처리보다 열처 리가 간섭효과를 제거하는데 더 효과적이었으며 온도와 시 간이 증가할수록 그 효과가 증가하는 것으로 나타났다. T-P 측정결과 역시 열처리가 간섭 제거에 효과적이었으나, T-P 가 여전히 과잉측정되어 이에 대한 추가적인 연구가 필요하다.

3) 본 연구를 통해서 세 지표를 동시에 측정할 수 있는 습
식산화방법의 적용 가능성을 확인하였다. 뿐만 아니라 고온 연소산화방식(HTC)에 비해 훨씬 낮은 온도에서 반응이 진 행되므로 에너지 소비와 장비 유지관리 측면에서 유리하게 작용할 수 있을 것으로 기대된다. 그러나 오차를 줄이고 정 확도를 향상시키기 위해 방해요인을 효과적으로 제거할 수 있는 방법에 대한 연구가 추가적으로 필요하다.

\section{Acknowledgement}

본 연구는 그린패트롤기술개발사업단의 지원을 받아 수 행되었음.

\section{References}

1. J. Schwarzbauer, S. Heim, S. Brinker, R. Littke, Occurrence and alteration of organic contaminants in seepage and leakage water from a waste deposit landfill, Water Res., 36(9), 2275-2287(2002).

2. I. Ali, M. Asim, T. A. Khan, Low cost adsorbents for the removal of organic pollutants from wastewater, J. Environ. Manage., 113, 170-183(2012).

3. O. Thomas, H. Khorassani, E. Touraud, H. Bitar, TOC versus UV spectrophotometry for wastewater quality monitoring, Talanta, 50(4), 743-749(1999).

4. J. Lee, S. Lee, S. Yu, D. Rhew, Relationships between water quality parameters in rivers and lakes: $\mathrm{BOD}_{5}, \mathrm{COD}, \mathrm{NBOPs}$, and TOC, Environ. Monit. Assess., 188(4), 252(2016).

5. S. Yang, P. Wang, X. Yang, L. Shan, W. Zhang, X. Shao, R. Niu, Degradation efficiencies of azo dye Acid Orange 7 by the interaction of heat, UV and anions with common oxidants: persulfate, peroxymonosulfate and hydrogen peroxide, J. Hazard. Mater., 179(1-3), 552-558(2010).

6. W. Bourgeois, J. E. Burgess, R. M. Stuetz, On line monitoring of wastewater quality: a review, J. Chem. Technol. Biotechnol., 76(4), 337-348(2001).

7. F. Wilson, Total organic carbon as a predictor of biological wastewater treatment efficiency and kinetic reaction rates, Water Sci. Technol., 35(8), 119-126(1997). 
8. M. N. Khan, F. Mohammad, Eutrophication: challenges and solutions, Eutrophication: Causes, Consequences and Control, A. Ansari, S. Gill (Eds.), Springer, Dordrecht, Netherlands, pp. 1-15(2014).

9. X. Jin, Q. Xu, C. Huang, Current status and future tendency of lake eutrophication in China, Sci. China Life Sci., 48(2), 948-954(2005).

10. J. G. Ferreira, J. H. Andersen, A. Borja, S. B. Bricker, J. Camp, M. C. da Silva, E. Garcés, A.-S. Heiskanen, C. Humborg, L. Ignatiades, C. Lancelot, A. Menesguen, P. Tett, N. Hoepffner, U. Claussen, Overview of eutrophication indicators to assess environmental status within the European Marine Strategy Framework Directive, Estuarine Coastal Shelf Sci., 93(2), 117-131(2011).

11. V. H. Smith, Eutrophication of freshwater and coastal marine ecosystems a global problem, Environ. Sci. Pollut. Res., 10(2), 126-139(2003).

12. H. Xu, H. W. Paerl, B. Qin, G. Zhu, G. Gaoa, Nitrogen and phosphorus inputs control phytoplankton growth in eutrophic Lake Taihu, China, Limnol. Oceanogr., 55(1), 420-432(2010).

13. W. K. Dodds, V. H. Smith, Nitrogen, phosphorus, and eutrophication in streams, Inland Waters, 6(2), 155-164(2016).

14. K. Y. Jung, K.-L. Lee, T. H. Im, I. J. Lee, S. Kim, K.-Y. Han, J. M. Ahn, Evaluation of water quality for the Nakdong River watershed using multivariate analysis, Environ. Technol. Innovation, 5, 67-82(2016).

15. B. M. De Borba, R. F. Jack, J. S. Rohrer, J. Wirt, D. Wang, Simultaneous determination of total nitrogen and total phosphorus in environmental waters using alkaline persulfate digestion and ion chromatography, J. Chromatogr. A, 1369, 131-137(2014).

16. W. Maher, F. Krikowa, D. Wruck, H. Louie, T. Nguyen, W. Y. Huang, Determination of total phosphorus and nitrogen in turbid waters by oxidation with alkaline potassium peroxodisulfate and low pressure microwave digestion, autoclave heating or the use of closed vessels in a hot water bath: comparison with Kjeldahl digestion, Anal. Chim. Acta, 463(2), 283-293(2002).

17. L. W. Matzek, K. E. Carter, Activated persulfate for organic chemical degradation: a review, Chemosphere, 151, 178-188 (2016).

18. J.-G. Kim, S.-M. Park, M. E. Lee, E. E. Kwon, K. Bae,
Photocatalytic co-oxidation of As(III) and Orange G using urea-derived $\mathrm{g}-\mathrm{C}_{3} \mathrm{~N}_{4}$ and persulfate, Chemosphere, 212, 193-199(2018).

19. C. Liang, H.-W. Su, Identification of sulfate and hydroxyl radicals in thermally activated persulfate, Ind. Eng. Chem. Res., 48(11), 5558-5562(2009).

20. O. S. Furman, A. L. Teel, R. J. Watts, Mechanism of base activation of persulfate, Environ. Sci. Technol., 44(16), 6423-6428(2010).

21. H.-B. Kim, J.-G. Kim, J.-H. Choi, E. E. Kwon, K. Baek, Photo-induced redox coupling of dissolved organic matter and iron in biochars and soil system: enhanced mobility of arsenic, Sci. Total Environ., 689, 1037-1043(2019).

\section{Authors}

\section{Jeong-Hwan Choi}

Department of Environment \& Energy and Soil Environment Research Center, Jeonbuk National University, M.S. Student, ORCID(1) 0000-0002-5754-6544

\section{Dong-Hun Shin}

Department of Environment \& Energy and Soil Environment Research Center, Jeonbuk National University, M.S. Student, ORCID(1) 0000-0001-5303-5221

\section{Hye-Bin Kim}

Department of Environment \& Energy and Soil Environment Research Center, Jeonbuk National University, Ph.D. Student, ORCID(10 0000-0003-4403-2461

\section{Jong-Gook Kim}

Department of Environment \& Energy and Soil Environment Research Center, Jeonbuk National University, Ph.D. Student, ORCID(i) 0000-0003-1502-6492

\section{Kitae Baek}

Department of Environment \& Energy and Soil Environment Research Center, Jeonbuk National University, Professor, ORCID(D) 0000-0002-7976-6484 